\title{
Team Ethical Cultures Within an Organization: A Differentiation Perspective on Their Existence and Relevance
}

\author{
Guillem C. Cabana ${ }^{1} \cdot$ Muel Kaptein ${ }^{1}$
}

Received: 3 December 2018 / Accepted: 2 December 2019 / Published online: 13 December 2019

(c) The Author(s) 2019

\begin{abstract}
Studies on the ethical culture of organizations have mainly focused on ethical culture at the organizational level. This study explores ethical culture at the team level because this can add a more detailed understanding of the ethics of an organization, which is necessary for more customized and effective management interventions. To find out whether various teams within an organization can have different ethical cultures, we employ the differentiation perspective and conduct a survey of 180 teams from one organization. The results show that there are significant differences between the ethical cultures of teams. These differences are relevant given the different relationships that were established between high and low clusters of team ethical culture and two outcome variables (i.e., the frequency of unethical behavior and employee responses to unethical behavior). The results also show that the dimensions of ethical cultures among teams have different patterns, which indicates the usefulness of using a multidimensional scale for capturing further differences among team ethical cultures.
\end{abstract}

Keywords Team ethical culture · Organizational ethical culture $\cdot$ Ethics management $\cdot$ Differentiation perspective . Corporate ethical virtues

The ethical culture of organizations is an important research topic, one that has received much attention in recent years (DeBode et al. 2013; Huhtala et al. 2016; Kangas et al. 2017; Riivari and Lämsä 2014; Treviño et al. 2014; Warren et al. 2014). There are several reasons for this. The ethical culture of an organization is supposed to be an antecedent of the ethical behavior of its employees (Kaptein 2011a; Treviño et al. 1998) and their willingness to report unethical behavior (Kaptein 2011b; Zhang et al. 2009a, b). In addition, the ethical culture of organizations has been positively associated with other organizational outcomes, such as innovation (Riivari and Lämsä 2014) and employee well-being (Kangas et al. 2017). There have also been empirical studies on the possible antecedents of the ethical culture of organizations, such as national cultures (Ardichvili et al. 2012; Burnaz et al. 2009) and ethics programs of organizations (Desplaces et al. 2007; Kaptein 2009; Warren et al. 2014).

Guillem C. Cabana

casolivaicabana@rsm.nl

Muel Kaptein

mkaptein@rsm.nl

1 RSM Erasmus University Rotterdam, Room T11-52, P.O.

Box 1730, 3000 DR Rotterdam, The Netherlands
Many of the studies on the ethical culture of organizations consider ethical culture to be homogeneous and unitary within an organization and to be distinctive between organizations. For example, many researchers talk about the ethical culture of an organization (e.g., Warren et al. 2014; Zaal et al. 2017; Zhang et al. 2009a, b). Mayer (2014) highlighted in his review of the ethical culture literature that most studies use an organizational level of analysis where the differences between the ethical cultures of organizations are used to explain differences in outcomes between organizations (e.g., Douglas et al. 2001; Hunt et al. 1989; Koh and Boo 2004; Tsai and Shih 2005). Kaptein (2008) also found that ethical cultures between organizations differ significantly. Explicitly or implicitly assuming the homogeneity of the ethical culture of an organization pertains to what Martin (2002) calls the integration perspective of organizational culture.

Opposed to the integration perspective of organizational culture is the differentiation perspective. According to Martin (2002), this perspective is interesting because it views the organizational culture as a composite of different subcultures or cultures at the suborganizational level, such as the team, division, and hierarchy. Trice and Beyer (1993) and Schein (2007) also theorized about the existence of subcultures within organizations, and there have 
been evidence that subcultures within an organization form around occupations (Van Maanen and Barley 1984), sites (Sackmann 1997), ethnicity and gender (Bell 1990), national groups (Hofstede 1998a), organizational roles (Barley 1986), hierarchical levels (Brunsson and SahlinAndersson 2000), and teams (Glisson and James 2002). When there are also different subcultures formed around the ethics of an organization, it is necessary to examine the ethical cultures at the suborganizational level to better understand and manage the (bigger) ethical culture of that organization.

Although some studies have measured the ethical culture at the suborganizational level when examining various organizational outcomes, this has not been sufficient to determine whether different ethical cultures exist within an organization. For example, Schaubroeck et al. (2012) explored the influence of the shared ethical culture of teams within a military organization on the relationship between ethical leadership and ethical behavior, and Huhtala et al. (2015) studied the shared ethical culture of work groups as an antecedent of employee well-being. These studies are important in showing that ethical subcultures may be relevant when studying leadership and well-being at suborganizational levels; however, whether the differences between ethical subcultures are statistically significant remains unexamined.

The contribution of our study is the claim that many different ethical cultures can exist within an organization. To date, neither this possibility nor the significance of the differences between ethical cultures within an organization have been studied in the literature. More specifically, this study focuses on the differences between team ethical cultures because teams are an important unit of management and analysis within organizations (Glisson and James 2002). We use the Corporate Ethical Virtues Model (Kaptein 2008), which consists of eight dimensions, to extend our explorations along the following lines. First, we examine whether different team ethical cultures can exist within a large organization by comparing each team's aggregated score on all eight dimensions of ethical culture. Second, we analyze in two ways whether the differences in team ethical cultures are relevant for organizations. We examine whether the dimensions of ethical cultures among teams can have different patterns, operationalized as the order of and distance between the eight dimensions from the most to least embedded. Different patterns indicate that each type of pattern needs different management interventions. We also examine whether the differences in team ethical cultures can lead to different organizational outcomes operationalized as the frequency of perceived unethical behavior and the responses of employees to them. To test the differences and relationships, we used a sample of 180 teams from a private organization in the United Kingdom.
We start with an overview of the theoretical background of the study, focusing on the concepts of organizational culture, team culture, and ethical culture. We then present our hypotheses and describe the method and results of our empirical study. We conclude with a discussion of the implications of our results for extant theory and future research.

\section{Theoretical Background and Hypotheses}

\section{Team Culture}

Organizational culture is defined as the learned and shared assumptions, values, and behaviors of members of an organization (Schein 2007). Organizational culture, as suggested by Schein, consists of three different layers: a (deepest) layer of assumptions and shared meanings, a middle layer of values, and a surface layer of more observable factors such as behaviors that reflect those assumptions and shared meanings. Organizational climate is the other often-named component of the informal organizational context (Schneider et al. 2013). Although the differences between the two constructs of organizational climate and culture are disputedfor example by Denison (1996) and Schneider et al. (2017) they can be distinguished from each other following Glisson and James (2002): climate is the way people perceive their work environment (property of the individual), and culture is the way things are done in an organization (property of the organization). Organizational culture has been shown to be important for organizational outcomes. For example, Sackmann's (2011) literature review of 55 studies empirically supports a direct association between organizational culture and various organizational performance measures, such as sales growth, market share, customer satisfaction, and product development.

Team culture encompasses the assumptions, values, and behaviors shared by individuals working together on a daily basis within the same suborganizational unit (Schein 2007). There are various terms used in the literature to refer to "team"; for instance, scholars interchangeably use "subgroup" (Earley and Mosakowski 2000), "group" (Liden et al. 2014), or "unit" (Glisson and James 2002). Ashkanasy et al. (2000) argue that the culture of organizations is inherently multilevel and that the team is one of the main levels of analysis, alongside the individual, organizational, and societal levels (e.g. Chao 2000; Glick 1985).

Team culture is different from organization culture and belongs to a separate level of analysis. While the latter comprises the shared assumptions, values, and behaviors across the organization, the former refers to the cultural differences and similarities at the team level. Research on the different aspects of team culture has yielded empirical evidence for positive associations with unit-level outcomes, such as 
performance (Liden et al. 2014) and learning (ZellmerBruhn and Gibson 2006), and individual-level outcomes, such as job satisfaction, commitment, and turnover (Glisson and James 2002).

Different cultures within an organization, as Schein (2007) posits, can emerge due to a process of differentiation or division of labor that creates smaller units, such as teams, which then begin an independent process of team culture formation with their respective leaders. Thus, for organizations that successfully age and grow, the coordination of the business from a single team becomes more complicated and costlier with an increasing number of employees, products, services, and customers. All teams start with some type of originating event, although mostly this is due to management decisions related to business needs. Next, teams evolve in different stages over time, starting with only the leader knowing what to do, and then as they mature working together, team members get to know and accept each other and understand how they can perform effectively (Schein 2007).

Martin (2002) emphasizes that the resulting constellation of team cultures within an organization can be viewed from one of three perspectives - an integration, differentiation, or fragmentation perspective-depending on the level of consensus within and among teams. An integration perspective, that focuses on the shared cultural elements or dimensions across the organization, assumes a homogenous culture and therefore, that all team cultures are similar to and consistent with an overarching organizational culture. A differentiation perspective views the organizational culture as a composite of subcultures that differ from each other and do not form a consistent organizational culture. A fragmentation perspective does not focus on consistency, shared values, assumptions, or behavior within an organization or within teams. This perspective highlights the lack of internal agreement within groups regarding cultural manifestations and the importance of ambiguity.

However, neither Schein (2007) nor Martin (2002) explicitly examines the cultural manifestation of the ethical dimensions of culture. It remains unexplored whether ethical culture and its dimensions might differ within an organization (e.g., among teams) and whether as a result, different ethical cultures at suborganizational level might exist. To shed light on the effects of the differentiation process on the ethical dimensions of culture, it is necessary to first understand clearly what a team ethical culture is.

\section{Team Ethical Culture}

Organizational ethical culture theory and research can be considered a subset of the organizational culture literature (Treviño et al. 1998). According to Mayer's (2014) review of the ethical culture literature, there is hardly any consistency in the use of measures of ethical culture, which then leads to construct validity problems. Mayer identifies three primary conceptualizations and operationalizations of ethical culture: the Corporate Ethical Values (Hunt et al. 1989), the Ethical Culture Index (Treviño et al. 1998), and the Corporate Ethics Virtues Model (Kaptein 2008). For Hunt and colleagues, an important aspect of an organization's ethical culture is the ethical values of the organization, for which they propose a five-item measure that focuses on the occurrence of unethical behavior by managers, the degree to which employees have to compromise their own ethics at work, and whether wrongdoers in the organization are held accountable. Treviño et al. proposed the Ethical Culture Index, a 21-item measure centered on aspects of the ethical environment, obedience to authority, and code of ethics implementation. This 21-item measure differs from the measures of Kaptein and of Hunt and colleagues by combining both informal (e.g., values, behaviors) and formal elements (e.g., code of ethics) to define ethical culture. Kaptein developed the Corporate Ethics Virtues (CEV) model, drawing from Solomon's virtue-based theory of business ethics that suggests that organizations themselves possess virtues or conditions that foster ethical behavior and prevent unethical behavior. The CEV model is a 58-item measure of ethical culture, with eight ethical virtues or dimensions. The first dimension is clarity of ethical standards, which refers to concrete and understandable expectations. The second and third dimensions reflect managerial behavior: the ethical role modeling by supervisors and (senior) management. The fourth is feasibility, which is the opportunity or ability to behave ethically based on resources available (e.g., time, information, equipment). The fifth is supportability, which refers to creating a shared commitment to ethical behaviors through fair treatment and mutual trust in the workplace. The sixth is transparency, which refers to the visibility of unethical behaviors and their consequences within the organization. Seventh is discussability, which is the opportunity to raise and discuss ethical issues. Finally, the eighth dimension is sanctionability, which is the likelihood of employees and managers being rewarded for ethical behavior and punished for unethical behavior.

Whereas Treviño et al. (1998) and Hunt et al. (1989) propose a one-dimensional scale of ethical culture, Kaptein (2008) develops a multidimensional scale to capture the dimensions of the ethical culture in organizations. Given that the aim of our study is to find out in what respect team ethical cultures differ (when they do differ), we have to use the CEV model because so far it is the only multidimensional scale of ethical culture. To preserve construct validity, the choice of the CEV model also reflects its recent use in many empirical studies on ethical culture (e.g., Huhtala et al. 2015, 2016, 2018; Kangas et al. 2016, 2017; Pučètaitè et al. 2016; Riivari and Lämsä 2014; Zaal et al. 2017). 
Consistent with our choice of CEV as a model, we define team ethical culture, following Kaptein (2009), as the shared set of experiences, assumptions, and expectations of managers and employees within a team about how the organization prevents them from behaving unethically and encourages them to behave ethically. In the remainder of this study, we refer to the different ethical cultures among teams as team ethical cultures (abbreviated as TEC).

As pointed out in the reviews of Treviño et al. (2006) and Mayer (2014), the study on TEC has received limited attention compared to the study on ethical cultures at the organizational level. Both reviews highlight the need for more studies on ethical culture at the team level. Martin (2002) argues that an explanation for this unevenness can be a bias towards the integration perspective in which scholars tend to choose an approach that emphasizes those dimensions on which there is a high degree of consensus across the organization. To the best of our knowledge, most of the empirical studies on ethical culture has implicitly used the integration perspective, while a minority have been implicitly based on the differentiation perspective. ${ }^{1}$ In other words, to date, empirical studies on ethical culture have not openly or explicitly stated or discussed their choice of theoretical perspective. Studies from an integration perspective do not focus on the differences between teams and examine mainly the ethical culture at the organizational level because ethical culture is conceived to be homogeneous across the organization. There have been a few published empirical studies on ethical culture at the team level (or similar types of groups within an organization, such as department and work group). Although none of these studies explicitly discussed which theoretical perspective on ethical culture they used, they can be considered as inherently based on the differentiation perspective. This is because these studies assume differences or variance in ethical culture among teams within an organization to study relationships with other organizational variables.

One of the first studies on ethical culture at the team level is Kaptein and van Dalen (2000). In their study, they explored the extent to which three departments of a Dutch

\footnotetext{
${ }^{1}$ Empirical studies on organizational ethical culture that follow an integration perspective are Ardichvili et al. (2012); Baker et al. (2006); Burnaz et al. (2009); Caldwell and Moberg (2007); Desplaces et al. (2007); Huhtala et al. (2013); Huhtala et al. (2011); Huhtala et al. (2016); Kangas et al. (2016); Kaptein (2010, 2011a); Keith et al. (2003); Koh and Boo (2004); Park and Blenkinsopp (2013); Pierce and Sweeney,(2010); Pučètaitė et al. (2016); Riivari and Lämsä (2014); Riivari et al. (2012); Ruiz-Palomino and Martínez-Cañas (2014); Sharma et al.,(2009); Sweeney et al. (2010); Tsai and Shih (2005); Valentine (2009); Valentine et al. (2011); Valentine et al. (2002); Valentine and Barnett (2007); Vitell and Hidalgo (2006); De Vries and van Gelder (2015); Webb (2012); Zaal et al. (2017); and Zhang et al. (2009a, b)
}

bank had anything in common because a large fraud was committed in only one of them. Descriptive results revealed a few significant differences in the dimensions of the ethical culture of the three departments, with the department where the fraud was committed scoring lowest. Kaptein (2011a) found a negative relationship between six dimensions of the ethical culture of teams and the frequency of observed unethical behavior. The sample of teams studied was from different organizations and thus it was not possible to establish whether TECs differ within one organization. Schaubroeck et al. (2012) studied how ethical leadership in a military organization plays a role in forming the ethical culture of work units. Interestingly, the study reported that larger units (platoons) had larger differences in terms of ethical culture than smaller units (squads). Although these variations in ethical culture across work units and hierarchical levels were used as a mediator, the study did not discuss the significance of such differences or the potential similarities between TECs.

More recently, Huhtala et al. (2015), Kangas et al. (2017), and Huang and Paterson (2017) studied ethical culture at the team level by using variance between groups as a reference to determine the shared experience of ethical culture within teams. The first two studies used the same Finnish publicsector organization as a sample and results showed that a proportion of the total variance regarding ethical culture was explained by team membership. Huhtala and colleagues confirmed that the more ethical the team culture was perceived to be, the less burnout and more work engagement were reported within the team. In contrast, Kangas and colleagues found that shared perceptions of ethical culture by team members were not associated with sickness-related absences at the team level. Moreover, Huang and colleagues found that ethical culture at the team level of stores mediated the positive relationship between upper-level ethical leadership and team ethical voice and that team ethical voice positively influenced team ethical performance.

In all the above-mentioned studies, TEC was found to be a predictor or moderator; this suggests a minimum degree of variance between the teams of the same organization. However, these studies only reported the standard deviations of the sample for TEC, which does not inform about the significance of the differences between TEC. Likewise, some of these studies reported the percentage of ethical culture variance explained by team membership; however, this alone does not clarify whether the differences are significant. Therefore, there lacks empirical evidence about the possibility of different TECs in an organization.

\section{Differences Among Team Ethical Cultures}

From a differentiation perspective, the basic foundation of team cultures is differential interaction. Because teams are 
formal groups in which employees work with each other on a daily basis, the interactions among team members are probably more frequent than interactions with employees outside the team. According to Trice and Beyer (1993), such interactions within teams provide one of the basis for the formation of subcultures. Social learning theory (Bandura 1977) helps explain how shared ethical culture can be created within teams through daily interactions and socialization between managers and employees. The ethical aspects of team culture are transmitted through socialization processes such as modeling, observation, and individual interaction among team members. These processes are important because the more team members interact, the more they tend to develop shared assumptions, values, and behaviors.

While TECs are expected to be consistent within teams through socialization, there may not be such consistency across TECs within organizations. Many organizational factors facilitate interaction among some employees but inhibit it among others. The result is a process of cultural differentiation that might fuel independent culture formation amongst teams. Schein (2007) lists five of such organizational factors: functional differentiation (related to occupation), geographical decentralization (related to continent, country or region), divisionalization (where different functions are (de)centralized), differentiation by hierarchical level (e.g., managers, nonmanagers, executives), and differentiation by product or market. While Trice and Beyer (1993) propose additional factors to foster differentiation, such as unionization or channels established for lateral and vertical communication, Glisson and James (2002) add managers as a factor that can foster the emergence of differentiated team cultures representing local properties of culture. To conclude, we come to the following hypothesis:

Hypothesis 1 The ethical culture of teams within an organization can differ from each other.

\section{Different Patterns of the Dimensions of Team Ethical Cultures}

Differences in the team ethical culture total scores among teams may not mean that all the individual scores for each dimension of the ethical culture among teams differ in the same way. For example, having an organization with teams with a high total score for ethical culture may not mean that all of the dimensions of the ethical culture of such teams score equally higher than those of the teams with a lower ethical culture. If the dimensions do not differ in the same way but show a distinction in their pattern or sequence, which is the order of and distance between the dimensions from the best embedded to least embedded, it is relevant to make this distinction and examine the different patterns. Ignoring those differences at the team level would risk ineffective management interventions to improve the ethical culture. For example, different interventions at the team level are required in an organization when within its teams with a high ethical culture, clarity is the best embedded of all the dimensions and the least embedded within its teams with a low ethical culture.

It is likely that the pattern of the dimensions of different TECs differ among teams within one organization. The factors that influence the differences in TECs may also have a different impact on each of the dimensions. For example, a team manager with an enabling leadership style will more likely create a TEC where the dimension of supportability scores higher and the dimension of sanctionability scores lower, while the opposite is more likely for a manager with a coercive leadership style (Bedi et al. 2016). Assessing the dimensions of ethical culture at only the organizational level may therefore ignore different patterns among teams within one organization. So we go one step further than Kaptein (2008), who found that dimensions of ethical culture at the organizational level are distinctive and relevant, by also studying whether dimensions of ethical culture at the team level are distinctive and relevant.

Some dimensions of the CEV model might be more closely related to the team level and, consequently, they should differ the most. The congruency of supervisors, for example, is basically related to how an individual supervisor acts within a team, and this perception might vary greatly among teams when there are many teams in an organization with each team having a different supervisor. In contrast, other dimensions more related to the organizational level and common to all teams, such as clarity in relation to the company values and norms, might show less variety between teams.

All eight dimensions form TEC but we expect five of them to be more influenced by the team level than by the organizational level. Congruency of supervisor, as previously mentioned, depends on the character and actions of the person who leads the team, which makes team members' experiences less similar to those of other teams. Although resources are distributed at the organizational level, feasibility is also highly dependent on the team level because the amount of available resources to carry out tasks the right way may vary substantially between teams due to business needs. Supportability is another dimension that is more influenced by the team level because it is through the behavior of team members that an employee perceives whether there is support for acting with integrity within a team. Discussability can be considered more dependent on the team level if we take into account that most of the daily conversations and interactions of employees, including ethics and compliance matters, happen within the team. Because the response (disciplinary or not) to unethical behavior is in the first instance determined by the supervisor who is in charge, 
this dimension may also be more influenced by the team level.

In contrast, congruency of management, clarity, and transparency are three dimensions that are less team specific and more influenced by the organizational level. Role modeling by the (senior) management of an organization can be known to the same extent by employees in all teams. The standards of conduct and norms written down in the company code of conduct are the same for everyone in the organization and can be implemented in the same way (e.g., mandatory training). Because a company code of conduct is applicable to every employee, we then expect less variety in clarity. Transparency is another dimension that may be more influenced by the organizational level. To ensure transparency, organizations rely on company-wide monitoring and audit systems. Thus, these mechanisms for detecting unethical behavior can be the same across the organization. Employees' perception of these three dimensions, which are more likely to be influenced by the organizational level, should tend to be less different than their perception of the dimensions that are more team specific. It is worth noting though that employee's perception of the dimensions that are more dependent on the organizational level may also be partially influenced by the team. For example, the perception of congruency of management may be shaped by how supervisors talk about management. Likewise, employee's perception of transparency and clarity may be also positively or negatively influenced by supervisors' opinions on company standards and communications.

With the distinction between dimensions being more influenced by either the team or the organizational level, we speculate that the teams with higher total TEC scores will have relatively higher specific team dimensions because they are the ones that are expected to differ the most. More specifically, we expect that only the dimensions of clarity, transparency, and congruency of management will not (or less) differ in their patterns within teams with higher and lower TEC because these dimensions are more influenced by the organizational level. At this point, we come to the second hypothesis:

Hypothesis 2 The pattern of the dimensions of different team ethical cultures can differ among teams within one organization.

\section{Different Outcomes of Different Team Ethical Cultures}

That the ethical culture among teams in an organization may differ is relevant when this difference leads to different organizational outcomes, such as frequency of unethical behavior. Otherwise, neither academic nor managerial implications regarding TEC would follow if ethical cultures differ among teams but the outcomes are similar. As mentioned above, Treviño et al. (1998) and Kaptein (2011a) have found that ethical culture at the organizational level is negatively related to observed unethical behavior. For example, Scholten and Ellemers (2016) have already found some indications of the influence of team ethical climates on the occurrence of misconduct in trading teams within a bank. Kaptein (2011b) also found that the ethical cultures of teams from different organizations are positively related to the intention to internally report observed unethical behavior. In a similar vein, we can expect that within the same organization, teams with a higher TEC will have more positive behavioral outcomes (e.g., willingness to report observed unethical behavior) and less negative behavioral outcomes (e.g., frequency of observed unethical behavior) than the teams with a lower TEC. In terms of the dimensions, we expect, for example, that the congruency of supervisors in teams with a higher TEC will be associated with positive responses to unethical behavior, such as the intention to report, while we do not expect this relationship in teams with lower TEC. So our third and final hypothesis, is:

Hypothesis 3 Different team ethical cultures within one organization can lead to different outcomes.

\section{Methods}

\section{Sample and Procedure}

Our sample consisted of all the 1720 employees of a British private organization. This organization works in the online travel industry and all four sites are located in the same city in the United Kingdom. All employees received an invitation to complete the electronic survey. Completion of the survey was anonymous and was awarded with one credit equivalent to a mandatory 20-min compliance online course. There were 1545 employees who fully completed the survey, yielding a response rate of $89.8 \%$. Due to missing information regarding the respondents' work team, the useable dataset was reduced to 1456 . In line with the methodological recommendations of Maloney et al. (2010), the minimum number of responding team members necessary for inclusion in this study was three per team. We omitted 21 teams that did not meet this requirement. The final sample consisted of 1378 managers and employees divided into 180 work teams.

In our study, we used Shin et al. (2012) definition of a work team: a group of personnel that (1) forms the smallest functional unit in the organization, (2) reports directly to the same manager, and (3) works together on a permanent basis. The main job functions across the organization were customer service (e.g., attending customer via phone, email, or chat), customer experience (e.g., software engineering, 
product design), and support (e.g., HR, compliance, finance). These three main functions were located at different sites in the same city. For our study, a team comprised of team members who worked at the same site, did similar jobs related to one of the specific job functions described above, and had the same manager.

Managers (including supervisors) were not considered members of the teams they managed; instead they were grouped with other managers with the same hierarchical level and function and who reported to the same senior manager. We did this because otherwise managers' experiences would have been "drowned" by the experiences of the subordinates (Hofstede 1998a, p. 6) given that the former were essentially different from the latter. Although managers shared the same physical location with their subordinates, they had different job descriptions (e.g., objectives, managerial duties), and they did not report to the same individual as their subordinates did. As a result, managers could be punished and rewarded for their behavior by their superiors in ways different from how their subordinates would be punished and rewarded. In addition, managers reporting to the same (senior) manager frequently met each other during management team meetings, were part of the same email list (equal access to information) and were located in the same site. Therefore, it was reasonable to consider the managers in the study as separate teams.

The majority (60.6\%) of the participants were male, and $76 \%$ were younger than 41 years old. Slightly over a third (35.1\%) of the respondents had been working in the organization for over 2 years, while a majority (64.9\%) had been working for less than 2 years. On average, teams consisted of 7.6 members $(\mathrm{SD}=4.15)$. The proportion of respondents with managerial tasks was $21 \%$.

\section{Measurements}

\section{Ethical Culture}

To assess TEC, we used Kaptein's (2008) CEV model because of its multidimensional nature. Specifically, we relied on the shortened 32-item version of the CEV Model developed by DeBode et al. (2013). Following Kaptein's scale (2008), we measured the items using a 6-point Likert-type scale ranging from " $1=$ strongly disagree" to " $6=$ strongly agree". Reliability (Cronbach's alphas) of all the dimensions, depicted on the diagonal of Table I, was above the minimum of 0.70 , as recommended by Nunnally (1978).

\section{Outcome Variables}

To assess the outcomes that were relevant for testing Hypothesis 3, we used four variables: observed unethical behavior and three types of responses to unethical behavior: internal reporting, external reporting, and directly resolving the matter. We captured observed unethical behavior using the item, "Have you observed unethical behavior in your team against the organization's code of conduct in the last 12 months?" The responses were recorded in a binary option: " $0=$ No" and " $1=$ Yes". Following Treviño et al. (1998) and Schaubroeck et al. (2012), this item referred to personal observations of unethical behavior exhibited by other employees rather than to self-reported behavior. This reduced the problem of social desirability bias. The organization's code of conduct, a 44-page document that describes the ethical and legal requirements governing the business, had been distributed to every employee. The content of the code of conduct defines what is considered unethical behavior in the following aspects: harassment, discrimination, threats, conflict of interest, insider trading, bribery and corruption, financial misconduct, and any violation of internal policies such as data security, international trade, fair competition, gifts and entertainment, and protection of company assets. The code of conduct also requires employees to speak up and report any suspected violation of the code of conduct, regardless of the hierarchical position of the offender, by establishing a nonretaliatory policy. Because the code of conduct is publicly available and all new hires need to sign it before joining the company, it is expected that all employees and managers employed by the company will use their knowledge of the content of the code of conduct when determining whether an action violates the code and is thus unethical in the context of work. The 12-month period referred to in the item has already been used in other empirical studies involving unethical behavior (e.g., Kaptein 2008; Treviño et al. 1998). In order to exclude the effect of team size on unethical behavior (because the more members in a team, the more people could behave unethically and the more likely that the frequency of unethical behavior would be higher), we calculated the ratio between the frequency of observed unethical behavior and the number of team members.

In keeping with studies conducted by Ayers and Kaplan (2005) and Kaptein (2011b), we requested the respondents to indicate what they think they would do if they were to observe unethical behavior in their organization. We captured the intention to report unethical behavior within the organization with the question, "If you were to observe unethical behavior, would you feel comfortable to report to" with five different possible recipients: supervisor, senior management, human resources, compliance officer, and compliance hotline. In this organization, the compliance officer belonged to the Legal \& Compliance department and reported directly to the CEO. The compliance officer was thus independent from the HR department. Respondents had to separately rate whether they would feel comfortable reporting observed unethical 
behavior through each of the five reporting channels. Other possible responses to unethical behavior such as "trying to resolve the matter directly" and "notify someone outside the organization" were captured by similar questions: "If you were to observe unethical behavior, would you feel comfortable resolving the matter directly?" and "If you were to observe unethical behavior, would you feel comfortable reporting to an external authority outside the company?" The responses were recorded in a Likert scale from 1 to 6 , ranging from " $1=$ strongly disagree" to " $6=$ strongly agree". For internal reporting, the results per respondent were aggregated on the average of the five recipients. In including different recipients, the measure provided a more balanced test of employees' willingness to report unethical behavior within the organization in comparison to studies with a more conservative approach, such as Warren et al. (2014), which only included the compliance officer as recipient.

\section{Control Variables}

The following demographic control variables were used to consider additional factors that might explain the variance in TEC: hierarchical level of the team (with three categories: " $1=$ nonmanagerial level", " $2=$ managerial level", and " 3 = senior managerial level"); job tenure of team members in the organization (with four categories: " $1=$ less than 6 months", " $2=$ between 6 months and 1 year", and " 3 = between 1 and 2 years", and " $4=$ over two years"); and size of the teams (in number of employees).

\section{Data Analysis}

We performed the following analysis on the generated data. We calculated the mean for the ethical culture at team level through the team averages of the eight dimensions (from the CEV Model). The within-group interrater agreement index, $r_{\mathrm{wg}}$ (James et al. 1993) was used to assess whether the aggregation of data justified higher levels of analysis. To address the question of whether TECs resemble or differ from each other, we conducted a hierarchical cluster analysis (following Hofstede 1998b) and a multivariate analysis of variance. For Hypothesis 2, we examined the sequence of ethical culture dimensions at the organizational and team levels. For Hypothesis 3 , we used linear regression and logistic regression analyses to determine the implications of the differences in TEC for the frequency of observed unethical behavior and employees' responses to unethical behavior.

\section{Results}

\section{Preliminary Analysis}

In the development of this study, we took several steps to minimize concerns regarding common method bias. For instance, we followed many of the recommendations by Podsakoff et al. (2003). More specifically, we reminded participants that their responses were anonymous, we carefully used a highly validated scale, and we included different types of scales in the survey.

Table 1 depicts the means, standard deviations, and correlations of all study variables. The variance inflation factors were not greater than 10 , thus there did not seem to be any problems of multicollinearity despite certain high correlations. Ten is the rule of thumb to indicate multicollinearity problems (Ryan 1997). All dimensions of ethical culture were negatively correlated to observed unethical behavior and positively related to the intention to report unethical behavior. All dimensions of ethical culture were equally correlated with the ratio of observed unethical behavior per employee. The bivariate correlations with observed unethical behavior ranged from $r=-0.07$ $(p>0.01)$ for clarity of ethical behavior to $r=-0.38$ $(p<0.01)$ for sanctionability, while bivariate correlations with intention to report ranged from $r=0.54(p<0.01)$ for clarity to $r=0.70(p<0.01)$ for discussability. The frequency of the average ethical culture of the 180 teams showed a broad range of scores between 3.85 up to 5.75. The difference between the highest and the lowest team was 1.9. The median for ethical team culture scores across teams was 5.05.

\section{Within-Group Consistency and Between-Group Differences of Team Ethical Cultures}

To test Hypothesis 1, we first needed to justify why we composed measures of TEC based on the individual scores of team members. In other words, we needed to prove that individual responses of team ethical culture are sufficiently homogenous within teams and differ between teams. To do that, we used the within-group consistency of responses via $r_{\text {wg }}$ and the between-group differences via interclass correlation coefficient (ICC).

The term within-group consistency refers to the degree to which raters (team members) provide essentially the same rating (Bliese 2000). In our study, the average of $r_{\mathrm{wg}}$ found was 0.87 , which was acceptable because it did not fall below the 0.7-threshold that George (1990) and Nunnally (1978) recommended. The maximum $r_{\mathrm{wg}}$ score was 0.98 , while the minimum was at 0.53 . The inclusion of ten 
Table 1 Means, standard deviations, and correlations

\begin{tabular}{|c|c|c|c|c|c|c|c|c|c|}
\hline & Mean & SD & 1 & 2 & 3 & 4 & 5 & 6 & 7 \\
\hline 1. Clarity & 5.14 & 0.36 & $(0.91)$ & & & & & & \\
\hline 2. Congruency supervisors & 5.13 & 0.46 & $0.63 * *$ & $(0.93)$ & & & & & \\
\hline 3. Congruency managers & 4.91 & 0.42 & $0.69 * *$ & $0.56 * *$ & $(0.93)$ & & & & \\
\hline 4. Feasibility & 5.06 & 0.41 & $0.64 * *$ & $0.59 * *$ & $0.80 * *$ & $(0.89)$ & & & \\
\hline 5. Supportability & 5.05 & 0.42 & $0.56^{* *}$ & $0.67 * *$ & $0.59 * *$ & $0.60 * *$ & $(0.90)$ & & \\
\hline 6. Transparency & 4.78 & 0.45 & $0.57 * *$ & $=0.64 * *$ & $0.62 * *$ & $0.62 * *$ & $0.74 * *$ & $(0.91)$ & \\
\hline 7. Discussability & 5.00 & 0.43 & $0.66^{* *}$ & $0.73 * *$ & $0.67 * *$ & $0.70 * *$ & $0.75^{* *}$ & $0.81 * *$ & $(0.95)$ \\
\hline 8. Sanctionability & 4.79 & 0.43 & $0.61 * *$ & $=0.71 * *$ & $0.70 * *$ & $0.66^{* *}$ & $0.74 * *$ & $0.84 * *$ & $0.87 * *$ \\
\hline 9. Ethical culture total & 4.98 & 0.36 & $0.78 * *$ & $0.82 * *$ & $0.83 * *$ & $0.82 * *$ & $0.84 * *$ & $0.87 * *$ & $0.91 * *$ \\
\hline 10. Team size & 7.66 & 4.95 & 0.12 & 0.02 & -0.04 & -0.05 & $-0.15^{*}$ & -0.06 & -0.11 \\
\hline 11. Gender & 1.37 & 0.27 & 0.01 & -0.12 & 0.04 & -0.01 & -0.11 & -0.10 & $-0.17 *$ \\
\hline 12. Age & 2.00 & 0.26 & 0.03 & 0.04 & -0.03 & 0.06 & -0.01 & 0.02 & 0.05 \\
\hline 13. Tenure of respondents & 3.02 & 0.77 & 0.09 & -0.08 & -0.06 & -0.05 & -0.13 & -0.09 & -0.01 \\
\hline 14. Position of respondents & 1.35 & 0.55 & 0.12 & 0.03 & 0.03 & 0.13 & 0.09 & 0.03 & $0.20 * *$ \\
\hline 15. Observed unethical behavior & 1.13 & 1.58 & -0.07 & $-0.18^{*}$ & $-0.31 * *$ & $-0.25 * *$ & $-0.34 * *$ & $-0.30 * *$ & $-0.34 * *$ \\
\hline 16. Intention to report unethical behavior & 4.91 & 0.45 & $0.52 * *$ & $0.55 * *$ & $0.56 * *$ & $0.57 * *$ & $0.57 * *$ & $0.63 * *$ & $0.70 * *$ \\
\hline \multirow[t]{2}{*}{ 17. Ratio observed unethical behavior/employee } & 0.13 & 18 & -0.13 & $-0.16^{*}$ & $-0.31 * *$ & $-0.29 * *$ & $-0.26^{* *}$ & $-0.29 * *$ & $-0.30 * *$ \\
\hline & 8 & 9 & 10 & 11 & 12 & 13 & 14 & 15 & 16 \\
\hline
\end{tabular}

1. Clarity

2. Congruency supervisors

3. Congruency managers

4. Feasibility

5. Supportability

6. Transparency

7. Discussability

8. Sanctionability

$(0.88)$

9. Ethical culture total

$0.91 * * \quad(0.96)$

10. Team size

11. Gender

$-0.10 \quad-0.06$

11. Gender

$\begin{array}{lll}-0.09 & -0.08 & 0.17\end{array}$

12. Age

$-0.04 \quad 0.02$

13. Tenure of respondents

$-0.14 \quad-0.07$

0.13

0.12

14. Position of respondents

15. Observed unethical behavior

$0.06 \quad 0.10$

$-0.03$

$0.15^{*} \quad 0.28 * *$

$\begin{array}{lllll}0.38 * * & -0.33 * * & 0.66 * * & 0.17 * & 0.15 *\end{array}$

$0.45^{* *}$

16. Intention to report unethical behavior

$0.64 * * \quad 0.70 * *-0.14-0.11 \quad 0.19 *$

$0.13-0.12$

17. Ratio observed unethical behavior/employee

$-0.29 * *-0.30 * *$

$\begin{array}{lll}0.12 & 0.10 & 0.09\end{array}$

$0.16^{*}$

$0.29 * *-0.25 * *$

On the diagonal, Cronbach's alpha for ethical culture and its dimensions

$* * p<0.01, * p<0.05$

teams that were below the 0.7-level was in line with the argument of Liu et al. (2011) that when the average $r_{\text {wg }}$ is very high, like in our study (above 0.85 ), using only the valid data above the threshold is probably as good as using all data. As $r_{\mathrm{wg}}$ gets higher, the portion of the sample with low $r_{\mathrm{wg}}$ values decreases, hence the difference between using the complete sample and using only those observations with high interrater agreement values also decreases (Liu et al. 2011). We will further examine the theoretical implications of this choice in the discussion section below.
We examined the variance in team ethical culture by calculating the ICC to determine the respective proportions of the variance that were due to the team-unit level and to the individual level. The ICC (type 1), which is computed via a random intercepts model, indicates the proportion of total variance between teams, with values typically less than 0.20 (Bliese 2000). The ICC coefficient reported at 0.05 provided evidence of between-team differences. The coefficient of 0.05 indicated that the consistency of responses within each team was not merely due to highly consistent responses 
Fig. 1 Full and simplified dendrogram of team ethical culture, using average linkage (between groups)

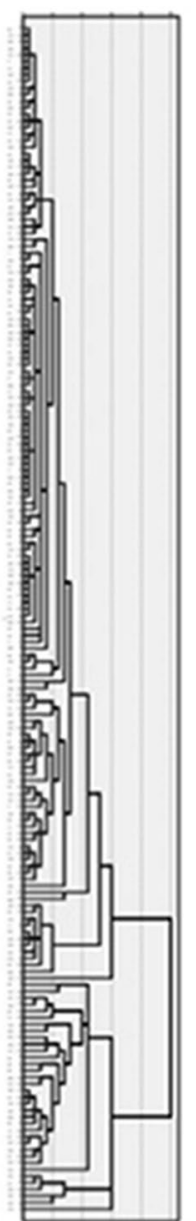

\section{Cluster Teams Rescaled Distance Cluster Combine}

01<smiles>[111InH]</smiles>

02

03

04

05

06

07

08

09

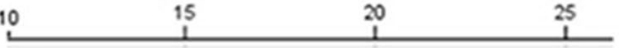

2

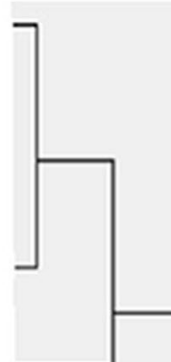

11

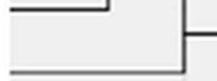

2

26

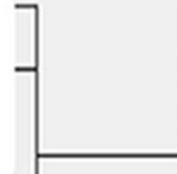

in the entire sample that included all teams. A meaningful composition of responses by teams to show differences was supported by between-team differences that accompany within-team similarities. These analyses showed that $5 \%$ of the total variance on TEC was explained by the team level. The variance in team ethical culture could also be explained by team characteristics that we did not measure fully. The ICC was also significant $(p<0.01)$.

To understand the differences found between TECs, we conducted two separate analyses: hierarchical cluster analysis and multivariate analysis of variance. Although differences between TECs exist on average (ICC), ICC values do not show differences in culture between teams. For example, a majority of unique teams can have similar aggregate scores for ethical culture, while some teams can have important differences compared to this majority. The resulting average may obscure the range of such differences because they may have balanced off (higher and lower TECs). For this reason, we started with the hierarchical cluster analysis. The mean scores on the eight dimensions of ethical culture for the 180 teams were subjected to a hierarchical cluster analysis using Ward's method (cf. Hofstede 1998b). In this statistical technique, teams and clusters of teams were combined one by one based on the similarity of their mean scores on the eight ethical dimensions. The process of combination is pictured in a dendrogram or tree diagram, similar to what more recent studies, such as Artis and Okubo (2009), have done.

Figure 1 is based on the dendrogram for the entire organization and includes the original dendrogram (on the left) and the reduced size dendrogram (on the right). The reduction shows only the right-hand part, cutting at a rescaled distance of 10 points, thus combining the 180 teams into 9 small clusters. The process of determining the optimal number of splits to be taken into account resembles the process of analysis in factor analysis: one limits oneself to the steps that lead to large jumps on the rescaled distance scale. As a result, we found an important split between clusters 1-4 and 5-9. Based on these scores, we labeled cluster 1-4 as teams with higher ethical subculture and cluster 5-9 as teams with lower ethical subculture. Further splits were more difficult to interpret because the distance between clusters was lower, which meant that different clusters at lower levels differentiated much less among themselves. For this reason, if no significant differences were found in the higher levels, it was reasonable to believe that neither would they be found 
Table 2 Results of MANOVA by teams $(N=180)$

\begin{tabular}{|c|c|c|c|c|}
\hline Team effect & $\begin{array}{l}\text { Wilks } \lambda=0.38 \\
\text { Univariate resu }\end{array}$ & $\begin{array}{l}F=34.43 \\
\text { lits }\end{array}$ & $p<0.001$ & $\begin{array}{l}\text { Partial } \\
\eta^{2}=0.62\end{array}$ \\
\hline Variable & $F$ & $p<$ & & \\
\hline Clarity & 91.91 & 0.00 & & \\
\hline $\begin{array}{l}\text { Congruency supe- } \\
\text { rior }\end{array}$ & 138.78 & 0.00 & & \\
\hline $\begin{array}{l}\text { Congruency Man- } \\
\text { agement }\end{array}$ & 104.83 & 0.00 & & \\
\hline Feasibility & 109.09 & 0.00 & & \\
\hline Supportability & 117.95 & 0.00 & & \\
\hline Transparency & 186.91 & 0.00 & & \\
\hline Discussability & 190.85 & 0.00 & & \\
\hline Sanctionability & 187.34 & 0.00 & & \\
\hline
\end{tabular}

in the lower levels. In any case, the analysis of such detailed differences was not necessary for this study.

The high ethical culture cluster included 145 teams and 1,129 individuals. The ethical culture mean of the teams was $5.12(\mathrm{SD}=0.23)$, with the highest score of 5.74 and lowest score of 4.74. Team demographic properties resembled closely the original sample. The low ethical culture cluster (5-9) included 35 teams and 250 individuals. The teams in this cluster had an average ethical culture at 4.41 $(\mathrm{SD}=0.22)$, with teams scoring a maximum of 4.72 and a minimum of 3.85. Demographic group properties mainly resembled the original sample except for the hierarchy level, which signaled a slightly lower presence of management teams in this cluster (1.25).

Table 2 displays the second step for testing Hypothesis 1 , with the results of the multivariate analysis of variance by the two clusters of higher and lower ethical subcultures. The results indicated a significant overall difference between the two clusters in the mean of their TEC $(F=34.43, p<0.001)$. Also, univariate analyses of variance revealed significant differences in all TEC dimensions $(p<0.001)$. The multivariate $n^{2}=0.62$ indicated that approximately $62 \%$ of the multivariate variance of the dependent variables were associated with the subculture (cluster) factor. Hypothesis 1 is therefore supported: there is a distinction between different TECs within an organization.

\section{Multidimensions of Team Ethical Cultures}

To test Hypothesis 2, we calculated the mean scores for all the ethical dimensions in each setting and determined the pattern of the dimensions for the two clusters (high and low ethical subcultures) and for the organizational pattern. Table 3 shows the results. In this table, we can see that the largest differences between clusters were found in the dimension of transparency (0.81), and the smallest in the dimension of clarity $(0.52)$. The organizational pattern differed for each cluster in four dimensions, and only supportability was ranked the same in all three sequences. The top dimension for the overall ethical culture was clarity, as it was for the cluster of high ethical subculture; while congruency of supervisors was the first dimension for the cluster of low ethical subculture. Despite slightly different orders, all three sequences shared the same top four dimensions (clarity, congruency of supervisors, feasibility, and supportability) and the same bottom four dimensions (congruency of management, transparency, discussability, and sanctionability).

Admittedly, differences among patterns of ethical dimensions exist but these differences are not large when we look at the order (there is no more than one difference order in the overall organizational pattern) or percentage differences (which range from 11 to 20\%). This supports Hypothesis 2: the pattern of dimensions of ethical culture at the team level can differ between teams, although the differences within this organization for the two clusters are quite small.

Table 3 The patterns of the ethical culture dimensions

\begin{tabular}{|c|c|c|c|c|c|c|c|c|}
\hline \multirow[t]{2}{*}{ Variables } & \multicolumn{8}{|c|}{ Sequence } \\
\hline & Clarity & $\begin{array}{l}\text { Congruency } \\
\text { supervisors }\end{array}$ & Feasibility & Supportability & Discussability & $\begin{array}{l}\text { Congruency } \\
\text { management }\end{array}$ & Sanctionability & Transparency \\
\hline Company $(n=180)$ & 1 & 2 & 3 & 4 & 5 & 6 & 7 & 8 \\
\hline Cluster EC high $(n=145)$ & $2 *$ & $1^{*}$ & 3 & 4 & 5 & 6 & $8^{*}$ & $7 *$ \\
\hline Cluster EC low $(n=35)$ & 1 & $3 *$ & $2 *$ & 4 & $6^{*}$ & $5^{*}$ & 7 & 8 \\
\hline $\begin{array}{l}\text { Absolut difference between } \\
\text { clusters }\end{array}$ & 0.52 & 0.77 & 0.64 & 0.67 & 0.78 & 0.65 & 0.77 & 0.81 \\
\hline $\begin{array}{l}\text { Relative difference between } \\
\text { clusters }\end{array}$ & $-11 \%$ & $-17 \%$ & $-14 \%$ & $-15 \%$ & $-18 \%$ & $-14 \%$ & $-18 \%$ & $-20 \%$ \\
\hline
\end{tabular}

*The pattern order is from the ethical dimension with the highest mean to the one with the lowest mean 
Table 4 Logistic regression for ethical culture and observed unethical behavior (UB) with a binary outcome "Not" (=0)" versus "observed UB" $(=1)$

\begin{tabular}{|c|c|c|c|c|c|}
\hline Variables & Stand. $\beta$ weights & Wald's & $p<$ & $R^{2}$ & $\begin{array}{l}\text { Unethical } \\
\text { behavior ( } \% \text { of } \\
\text { detected) }\end{array}$ \\
\hline \multicolumn{6}{|l|}{ High cluster $(n=1128)$} \\
\hline Step 1 (constant) & -1.93 & 465.58 & 0.00 & & $87.3 *$ \\
\hline \multicolumn{6}{|l|}{ Step 2} \\
\hline Clarity & 0.46 & 5.44 & $0.02 *$ & & \\
\hline Congruency supervisors & 0.04 & 0.05 & 0.82 & & \\
\hline Congruency management & -0.71 & 18.87 & $0.01 * *$ & & \\
\hline Feasibility & -0.17 & 1.07 & 0.30 & & \\
\hline Supportability & 0.23 & 1.47 & 0.23 & & \\
\hline Transparency & -0.29 & 2.94 & 0.09 & & \\
\hline Discussability & -0.18 & 0.72 & 0.40 & & \\
\hline Sanctionability & -0.45 & 5.33 & $0.02 *$ & & \\
\hline Ethical culture & & & & 0.23 & $89.5^{*}$ \\
\hline Variables & Stand. $\beta$ weights & Wald's & $p<$ & $R^{2}$ & $\begin{array}{l}\text { Unethical } \\
\text { behavior ( } \% \text { of } \\
\text { detected) }\end{array}$ \\
\hline \multicolumn{6}{|l|}{ Low cluster $(n=250)$} \\
\hline Step 1 (constant) & -1.13 & 58.97 & 0.001 & & 75.6 \\
\hline \multicolumn{6}{|l|}{ Step 2} \\
\hline Clarity & 0.68 & 6.88 & $0.01 * *$ & & \\
\hline Congruency supervisors & 0.15 & 0.56 & 0.45 & & \\
\hline Congruency management & -0.60 & 8.99 & $0.01 * *$ & & \\
\hline Feasibility & 0.03 & 0.01 & 0.90 & & \\
\hline Supportability & -0.33 & 1.76 & 0.19 & & \\
\hline Transparency & -0.21 & 0.69 & 0.41 & & \\
\hline Discussability & 0.02 & 0.00 & 0.96 & & \\
\hline Sanctionability & -0.59 & 4.47 & $0.03 *$ & & \\
\hline Ethical culture & & & & 0.33 & $81.2 *$ \\
\hline
\end{tabular}

$R^{2}=$ Nagelkerke's variance explained. All predictors have eight degrees of freedom

$* * p<0.01, * p<0.05$

\section{Regression of Clusters of Team Ethical Culture on Outcomes}

The relationship between TEC and observed unethical behavior and employees' responses to unethical behavior between the two clusters of TECs was analyzed by means of binary and linear regression analyses. We used TEC as a multidimensional model to test the link with unethical behavior and employees' responses to unethical behavior.

We first compared the descriptives of both clusters of TECs. The cluster with higher TECs showed a lower level of observed unethical behavior $(M=0.99$; $\mathrm{SD}=1.34)$, a lower ratio of observed unethical behavior per employee $(M=0.11$; $\mathrm{SD}=0.15)$, and a higher intention to report unethical behavior $(M=5.02 ; \mathrm{SD}=0.38)$. In contrast, the cluster with lower TECs showed a much higher level of observed unethical behavior at $1.74(\mathrm{SD}=2.24)$ and ratio of observed unethical behavior per employee at 0.23 , and the intention to report unethical behavior was much lower at $4.47(\mathrm{SD}=0.47)$.

To test Hypothesis 3, we performed a logistic regression of ethical culture on observed unethical behavior for the individuals within each cluster. Because the item for unethical behavior in our study was dichotomic, it directed our analysis to a logistic regression model. We tested for effects of the perception of ethical culture on the two clusters using a logistic regression with unethical behavior as the binary dependent variable. Table 4 shows that the cluster with lower TECs explained better the variance on the frequency of observed unethical behavior than the cluster with higher TECs did. Also, when we added ethical culture, the increase in the percentage of correct predictions improved by $1.2 \%$, while the increase for the cluster with lower TECs 
Table 5 Linear regressions for ethical culture and internal reporting

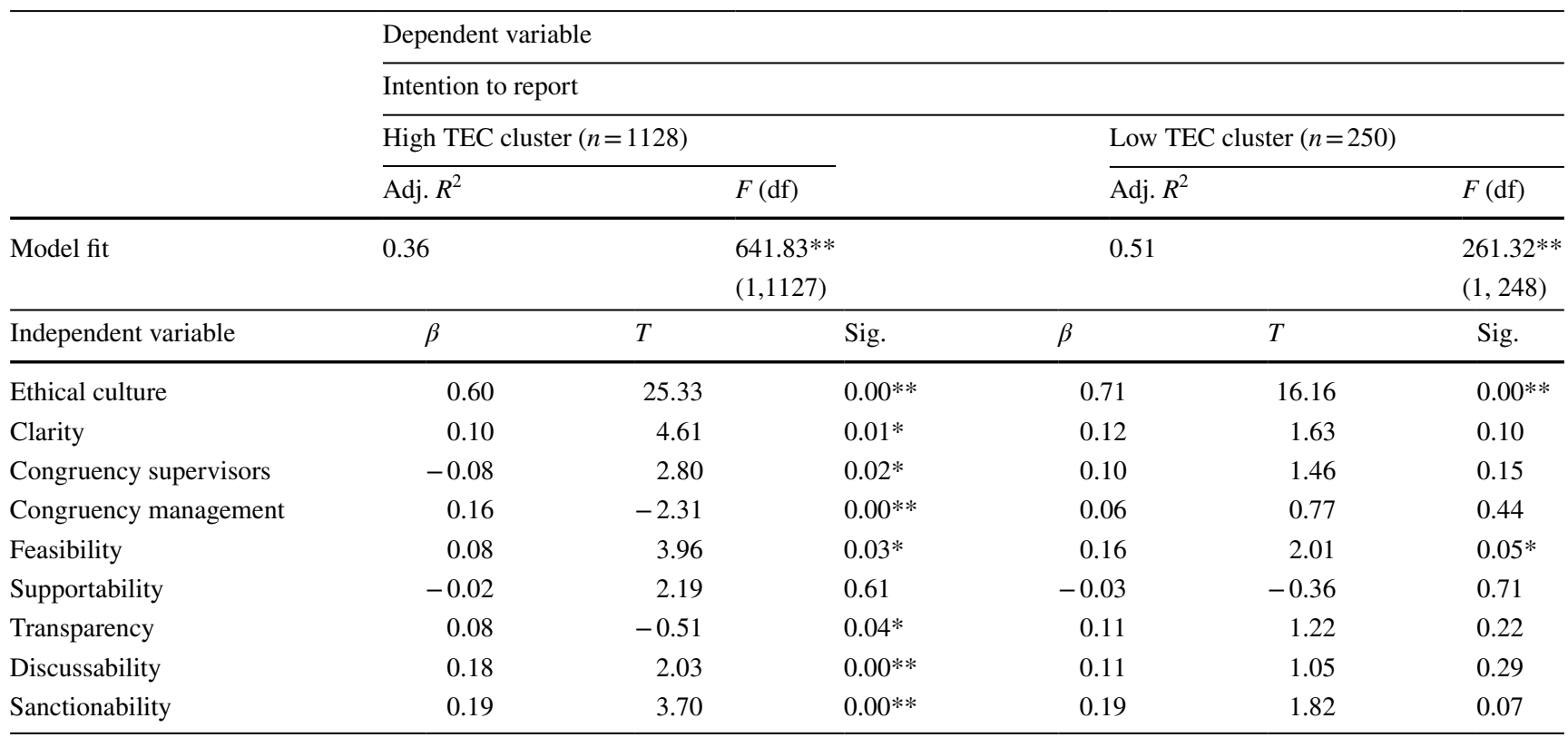

$* * p<0.01, * p<0.05$

(95\% confidence interval, $75.6 \%$ to $81.2 \%$ ) was almost three times, at $5.6 \%$.

The relationship between the dimensions of ethical culture and unethical behavior showed that three of the eight dimensions tested were significant in both clusters. Whereas clarity was positively related to observed unethical behavior, congruency of management and sanctionability were negatively related to observed unethical behavior.

Next, to test other organizational outcomes in relation to Hypothesis 3, we performed regression analysis for ethical culture on employees' responses to unethical behavior. Table 5 shows that in the cluster with higher TECs, the ethical culture model explained $36 \%$ of the intention to report within the organization (adj. $R^{2}=0.36 ; F=32.67 ; p<0.01$ ). In the cluster with lower TECs, ethical culture explained $50 \%$ of the intention to report (adj. $R^{2}=0.50 ; F=88.32$; $p<0.01$ ). This shows that the association between ethical culture and the intention to report might vary between teams. Table 5 also shows that in the cluster of higher TECs, there was a positive association between all the dimensions of TECs (except for supportability) and the intention to report unethical behavior. In the cluster of lower TECs, however, only the dimension of feasibility was significantly related to the intention to report unethical behavior. Table 6 shows that the cluster with lower TECs explained $17 \%$ of the intention to resolve the matter directly $\left(\operatorname{adj} . R^{2}=0.17 ; F=54.09\right.$; $p<0.01$ ), while the explanatory power of the cluster with higher TECs was lesser at $12 \%\left(\operatorname{adj} . R^{2}=0.12 ; F=26.69\right.$; $p<0.01$ ). The only dimensions of the ethical culture positively associated with resolving the matter directly were congruency of management and discussability in the cluster with higher TECs. Again, this showed differences between clusters of TECs because the cluster with lower TECs had no dimension associated with resolving the matter directly. Table 7 shows that ethical culture explained external reporting to an outside authority at just $5 \%$ for the cluster with higher TECs, while the explanatory relationship was not significant for the cluster with lower TECs. For the cluster with higher TECs, two dimensions of ethical culture positively associated with external reporting: transparency and sanctionability. The results confirm Hypothesis 3 because the differences between clusters of higher and lower TECs have different implications for the frequency of observed unethical behavior and the responses to observed unethical behavior.

\section{Discussion}

In this article, we used a differentiation perspective to study how TECs may differ and resemble within an organization. To assess how ethical culture may differ among teams, we collected the data of 180 teams from one organization. The relevance of this study was established by the significance of the differences between TECs and by the influence of clusters of TEC on the frequency of and different responses to observed unethical behavior.

The results show that on average, TECs have high withingroup agreement and moderate between-team differences. Team membership, or the shared experiences within a 
Table 6 Linear regressions for ethical culture and resolving unethical behavior directly

\begin{tabular}{|c|c|c|c|c|c|c|}
\hline & \multicolumn{6}{|c|}{ Dependent variable } \\
\hline & \multicolumn{6}{|c|}{ Addressing UB directly } \\
\hline & \multicolumn{3}{|c|}{ High TEC cluster $(n=1128)$} & \multicolumn{3}{|c|}{ Low TEC cluster $(n=250)$} \\
\hline & \multicolumn{2}{|l|}{$\overline{\text { Adj. } R^{2}}$} & $F(\mathrm{df})$ & \multicolumn{2}{|c|}{$\overline{\text { Adj. } R^{2}}$} & $F(\mathrm{df})$ \\
\hline Model fit & \multicolumn{2}{|l|}{0.12} & $\begin{array}{l}26.69 * * \\
(1,1127)\end{array}$ & \multicolumn{2}{|c|}{0.17} & $\begin{array}{l}54.09 * * \\
(1,248)\end{array}$ \\
\hline Independent variable & $\beta$ & $T$ & Sig. & $\beta$ & $T$ & Sig. \\
\hline Ethical culture & 0.69 & 12.13 & $0.00 * *$ & 0.63 & 16.16 & $0.00 * *$ \\
\hline Clarity & -0.04 & -4.88 & 0.62 & 0.22 & 1.48 & 0.14 \\
\hline Congruency supervisors & -0.46 & -0.60 & 0.55 & 0.02 & 0.19 & 0.84 \\
\hline Congruency management & 0.16 & 2.191 & $0.02 *$ & -0.06 & -0.55 & 0.58 \\
\hline Feasibility & 0.07 & 0.89 & 0.37 & 0.01 & 0.05 & 0.96 \\
\hline Supportability & -0.03 & -0.38 & 0.70 & -0.05 & -0.37 & 0.71 \\
\hline Transparency & 0.13 & 1.69 & 0.09 & 0.13 & 0.95 & 0.34 \\
\hline Discussability & 0.48 & 4.96 & $0.00 * *$ & 0.29 & 1.71 & 0.08 \\
\hline Sanctionability & -0.09 & -1.10 & 0.27 & 0.05 & 0.32 & 0.74 \\
\hline
\end{tabular}

$* * p<0.01, * p<0.05$

Table 7 Linear regressions for ethical culture and external reporting

\begin{tabular}{|c|c|c|c|c|c|c|}
\hline & \multicolumn{6}{|c|}{ Dependent variable } \\
\hline & \multicolumn{6}{|c|}{ External reporting } \\
\hline & \multicolumn{3}{|c|}{ High TEC cluster $(n=1128)$} & \multicolumn{3}{|c|}{ Low TEC cluster $(n=250)$} \\
\hline & Adj. $R^{2}$ & & $F(\mathrm{df})$ & $\overline{\text { Adj. } R^{2}}$ & & $F(\mathrm{df})$ \\
\hline Model fit & 0.05 & & $\begin{array}{l}4.63 * * \\
(1,1127)\end{array}$ & 0.01 & & $\begin{array}{l}0.84 \\
(1,248)\end{array}$ \\
\hline Independent variable & $\beta$ & $T$ & Sig. & $\beta$ & $T$ & Sig. \\
\hline Ethical culture & 0.16 & 2.15 & $0.03 *$ & 0.10 & 1.07 & 0.29 \\
\hline Clarity & -0.17 & -1.60 & 0.11 & 0.01 & 0.01 & 0.99 \\
\hline Congruency supervisors & -0.11 & -1.12 & 0.26 & 0.10 & 0.79 & 0.43 \\
\hline Congruency management & 0.02 & 0.16 & 0.86 & -0.09 & -0.69 & 0.49 \\
\hline Feasibility & -0.31 & -3.17 & 0.01 & 0.02 & 0.14 & 0.89 \\
\hline Supportability & -0.09 & -0.81 & 0.41 & 0.08 & 0.48 & 0.62 \\
\hline Transparency & 0.40 & 4.16 & $0.00 * *$ & 0.17 & 1.01 & 0.31 \\
\hline Discussability & -0.07 & -0.59 & 0.55 & 0.14 & 0.67 & 0.50 \\
\hline Sanctionability & 0.35 & 3.12 & $0.00^{* *}$ & -0.30 & -1.63 & 0.10 \\
\hline
\end{tabular}

$* * p<0.01, * p<0.05$

team, explained $5 \%$ of the variance of ethical culture. This is lower than the $12 \%$ to $27 \%$ that Huhtala et al. (2015) and Kangas et al. (2017) found in organizational ethical culture, and the $12 \%$ to $19 \%$ that Glisson and James (2002) found in team culture. In contrast, LeBreton and Senter (2008) have suggested that a $5 \%$ explanation of the variance represents a small to medium effect. Furthermore, Bliese (1998) simulated conditions where only $1 \%$ of the variance was attributed to group membership and yet strong group-level relationships were detected that were not evident in the lower-level data. Therefore, Hypothesis 1 is supported: the ethical culture of teams within an organization can differ from each other. 
Clustering TECs in hierarchical cluster analysis yielded interesting results. Following Hofstede's (1998b) empirical approach with the dendrogram, we observed that the constellation of TECs may form at least two differentiated clusters within the organization we studied, and we specifically characterized the clusters as either higher or lower ethical subcultures based on the scores of the ethical culture in each team. Compared to the lower-level cluster, the higher-level cluster showed lower levels of observed unethical behavior and higher levels of intention to report. Although it would have been possible, we did not try to interpret further splits in lower levels of the dendrogram. This is because the purpose of our study was to determine whether there were any differences among TECs and if these differences were significant. The MANOVA results suggest that the differences between the two clusters are significant, and this adds statistical support to the clustering choices during the analysis.

With regard to the patterns or sequences of the eight dimensions of ethical culture, it is necessary to understand that knowing the moderate to high correlations among the eight dimensions shown in Table 1 does not undermine the value of assessing team patterns. Although we found differences between the patterns of both clusters, these differences did not correspond to the more team-specific dimensions, contrary to our expectation. For example, we observed in both clusters of TECs, which differed in the sequences of dimensions, a combination of dimensions related to the team and organizational levels at the top four positions of the sequence. In fact, supportability was the only dimension that occupied the same position in the sequence in both clusters. A closer look suggests that the differences are best interpreted in terms of the compliance and integrity distinction. Treviño et al. (1999) argued that an integrity-based approach to ethics is more effective than a compliance-based approach. Role modeling (supervisors and management), discussability, and supportability are more like integrity-based dimensions because they refer to values and empowerment; while clarity, transparency, sanctionability are more like compliance-based dimensions because they refer to rules and discipline. Consequently, knowledge of patterns of TECs is important for determining whether TECs are either integrity- or compliance-oriented. Results in Table 3 show that the patterns of high TECs score relatively higher on integrity-based dimensions and relatively lower on compliance-based dimensions. Therefore, Hypothesis 2 on the existence of different patterns of the dimensions of TEC between clusters is confirmed.

Next, we found the differences in TEC to be relevant when we examined the outcomes, frequency of observed unethical behavior, and different responses to observed unethical behavior. That is, the relationships of different clusters of TECs with the outcomes showed sufficient differences, thus confirming Hypothesis 3.
We see both differences and similarities in the relationship of TEC with each outcome. With regard to the outcome variable, frequency of observed unethical behavior, the ethical culture in the cluster with lower TECs explained more variance than the ethical culture in the other cluster (higher TECs). One possible answer may be that the latter cluster had a low level of observed unethical behavior, which made it difficult to find predictors. This is because initially $87 \%$ of the cases were "predicted" correctly without including predictors. Only three of the eight dimensions of TEC tested in the relationship with observed unethical behavior were significant in both clusters. Whereas clarity was positively related to the observed unethical behavior, congruency of management and sanctionability were negatively related to the same. Kaptein (2011a) also found that, as expected, congruency of management and sanctionability had a negative relationship with observed unethical behavior, while clarity was not significantly related. In our study, the positive relationship between clarity in teams and observed unethical behavior may be because the clearer the norms, the more defined unethical behavior is and the more respondents label behavior as unethical. In addition, unlike Kaptein (2011a), we did not find in this study the negative relationships of congruency of supervisors, supportability, feasibility, and discussability with observed unethical behavior.

With respect to the outcome variable, intention to report observed unethical behavior within the organization, seven of the eight dimensions of ethical culture were significantly associated with it in the cluster of higher TECs. Supportability was not significantly associated with the intention to report unethical behavior. Of the seven dimensions, only congruency of supervisors was negatively related to this outcome variable. The more employees perceived role modeling in the immediate supervisor, the less they showed intention to report unethical behavior. This relationship is understandable if we consider that the variable intention to report is composed of the average of four additional recipients apart from the supervisor. When employees believe that they have a supervisor who is an ethical role model, they may feel more inclined to report directly to the supervisor and overlook other available reporting channels. In the cluster of lower TECs, only the dimension of feasibility was significantly related to the intention to report unethical behavior. Because the degree of variance explained by ethical culture on the intention to report is different between clusters of TECs, and the dimensions of ethical culture related to the intention to report unethical behavior also vary between clusters, it is reasonable to assume that the role of culture as a proxy to increase the intention to report observed unethical behavior may be more relevant in some teams.

When it came to resolving the matter directly as a response to observed unethical behavior, only the cluster with higher TECs showed dimensions of ethical culture that 
were significantly associated with this outcome variable. In particular, congruency of management and discussability were found to be positively associated with resolving the matter directly. It is reasonable to think that employees' perception of management's positive role modeling is likely to encourage them to act directly when they observe unethical behavior because of the belief that they have the backup of the higher-ups. However, the fact that employees experience openness in discussing ethical dilemmas within their team may make them more confident to informally call out others who seem to be behaving unethically (i.e., violating the code of conduct). In contrast, when we observed the relationship of ethical culture with the intention to report to some authority outside the organization, we found that the transparency and sanctionability dimensions were positively associated with this response, but only for the cluster with higher TECs. It is logical to think that employees who perceive that unethical behavior is promptly detected within their teams are more inclined to report not only within the organization (Table 5) but also externally. Latan et al. (2018) showed that organizational antecedents related to ethics improved both internal and external reporting intentions. Similarly, the perception that there is accountability-that unethical behavior is sanctioned within the organization-may increase not only employees' intention to report internally but also their inclination to report to authorities outside the organization.

\section{Future Research}

This study contributes to the understanding of the ethical culture of organizations by using the lens of the differentiation perspective on TECs. Our study shows that examining the ethical culture at the team level offers greater insights about the complexity of the construct within organizations and clarifies how ethical subcultures can be defined and understood according to the differentiation perspective. Based on this knowledge and on the use of clusters of higher and lower TEC in this study, new research strategies can be designed to extend scholarship on the differentiation perspective in business ethics, particularly to develop new typologies of ethical subcultures based on different characteristics of the clusters of TECs.

The findings of this study open up several avenues for future research. We discuss here four important ones. One promising research direction is to find out whether more than two ethical subcultures or clusters of TECs can be discerned in an organization so we can better model ethical culture at suborganizational levels. To find out the extent to which TECs within an organization can differ, our current study can be replicated in other organizations from other national cultures, industries, and group structures, different from the one we studied here. With regard to organizational subcultures in general, there has already been a considerable stream of research (Jung et al. 2015; Shin et al. 2015), for instance, how organizational subcultures may affect mergers and acquisitions (Van Marrewijk 2016), the implementation of corporate sustainability policies (Kok et al. 2017), and the rivalry between different military units and services such as conventional military and special operations forces (Soeters 2018). As to the topic of ethics, we expect a similar surge in research on identifying ethical subcultures based on team and other suborganizational levels and on examining relationships with various organizational outcomes. Knowing more about how ethical subcultures may affect important outcomes, such as actual reporting of unethical behavior or the occurrence of specific types of unethical behavior, could lead to important insights on differences within organizations.

A second promising research direction is to study the causes of cultural differentiation that create different TECs. TECs may be stimulated to be similar to each other when there are organization-wide measures to improve the organizational ethical culture, such as codes of conduct or ethics hotlines, which are usually the same for every employee within an organization (Kaptein 2015). The influence of senior management may also have an effect as it cascades down similar levels of TECs, from higher to lower hierarchical levels of an organization (Schaubroeck et al. 2012). However, as Schein (2007) argued, ethical culture among teams may differ due to their organizational factors, such as functions, geography, divisions, products/markets, and hierarchical levels. In the general organizational culture literature, Shin et al. (2012) found influences of team demographic diversity (e.g., nationality, age, tenure) on group-level outcomes. So it is likely that similar kinds of diversity may also influence the consistency or strength of TECs and fuel differentiation between them. Team members from different backgrounds may have a larger diversity of values (e.g., national, generational) than team members from similar backgrounds. Studies on other types of team cultures found the dimensions of flexibility-control and internal-external focus as explanations for team performance (Shin et al. 2015). In this sense, it is also promising to find out how ethical culture spreads between or among teams to prevent bad barrels (teams with low ethical cultures) from poisoning good barrels (teams with high ethical cultures) and to stimulate good barrels to heal bad ones. This would be different from the studies on how unethical behavior spreads within teams (e.g., Ariely 2008; Gino et al. 2009; Zuber 2015).

A third promising research direction is related to tailoring ethics programs for organizations. Many empirical studies on ethics programs within companies focus on the organizational level (Kaptein 2015; MacLean et al. 2015; SmithCrowe et al. 2015; Warren et al. 2014), which suggests that within an organization the same measures are taken for each 
employee in each team. For example, Kaptein (2009) studied the impact of ethics programs on organizational ethical culture by assessing the various components of these programs such as the code of ethics, ethics training and communication, and the ethics officer. Studying TECs then raises the interesting question to what extent the components of ethics programs have different impacts on TECs. By assessing the different impacts of these components on teams, we are then better able to tailor ethics program for organizations.

A fourth interesting research direction is to focus on specific dimensions of ethical culture and develop much more specific predictions about the outcomes of team variability. For example, perhaps variance on one dimension would be related to intra- and inter-team deviance, while variance on another dimension would be associated with more intra- and inter-team cooperation.

\section{Limitations of the Study}

One of the limitations of this study is the limited amount of time allocated by the company where we conducted our study for the employees to complete the survey. This affected the number of questions we could include in our study design. Many other studies on behavioral ethics have faced similar constraints (Warren et al. 2014). Due to these time limitations, we were not able to use an extensive scale (e.g., Kaptein's 2008, 37-item scale) to measure the frequency of observed unethical behavior.

A second limitation is that TEC and the organizational outcomes were measured exclusively through surveys from the same source. Whilst this quantitative method has the advantage of allowing population sampling and providing representative results for the overall organization, mixed methodologies including interviews and focus groups could have extended the depth and characterization of the ethical subcultures after they were identified by the surveys. Future research could also use nonperceptual data for the outcome variables, for example, the number of hotline reports and investigations per team, which would increase confidence to avoid common method bias.

\section{Implications for Management}

Our findings certainly have several implications for management. The most important of these is that to better understand their organization's ethical culture, management has to understand ethical culture at the team level. As our study found, the ethical cultures of the teams within an organization can differ, both in the average and relative scores of their dimensions. This could also be the case in other organizations, which can be more decentralized and larger than the one in this study. Different management interventions may be required to improve each of the differing TECs. Hence a much more tailored approach in managing ethics is needed and possible.

\section{Conclusion}

Much of past research on ethical culture has omitted theoretical views that explain the complexity and variation of ethical culture between teams within organizations. In this study, the differentiation perspective was used for the first time in relation to TECs. Our analysis suggests that TECs exist within organizations and can form differentiated clusters depending on the similarities and differences between teams. Our results show that at least two different clusters of TECs can be identified in the organization we studied. Furthermore, we found several interesting differences in the patterns of the ethical dimensions of the two ethical clusters and in their relationships with observed unethical behavior and intention to report unethical behavior. Based on the findings presented here, researchers should carefully consider and be transparent about the theoretical perspective they take when studying organizational ethical culture, and they should also account for team culture differentiation in their study designs. Future research on this topic should also seek explanations for ethical culture differentiation, combine different levels of study of ethical culture in and around organizations, and explore the implications of the existence of TECs for implementing ethics programs within organizations.

Acknowledgements We are grateful for the insightful comments on an earlier version of this article from the participants of the 2018 Annual Conference of the European Business Ethics Network.

Funding The author Guillem Casoliva author works as a senior ethics and compliance associate for the organization that took part in this study. He received time and permission from his employer to conduct and publish this study.

Open Access This article is licensed under a Creative Commons Attribution 4.0 International License, which permits use, sharing, adaptation, distribution and reproduction in any medium or format, as long as you give appropriate credit to the original author(s) and the source, provide a link to the Creative Commons licence, and indicate if changes were made. The images or other third party material in this article are included in the article's Creative Commons licence, unless indicated otherwise in a credit line to the material. If material is not included in the article's Creative Commons licence and your intended use is not permitted by statutory regulation or exceeds the permitted use, you will need to obtain permission directly from the copyright holder. To view a copy of this licence, visit http://creativecommons.org/licenses/by/4.0/. 


\section{References}

Ardichvili, A., Jondle, D., Kowske, B., Cornachione, E., Li, J., \& Thakadipuram, T. (2012). Ethical cultures in large business organizations in Brazil, Russia, India, and China. Journal of Business Ethics, 105(4), 415-428. https://doi.org/10.1007/s1055 1-011-0976-9.

Ariely, D. (2008). Predictably irrational: The hidden forces that shape our decisions. New York: Harper Perennial.

Artis, M., \& Okubo, T. (2009). Globalization and business cycle transmission. The North American Journal of Economics and Finance, 20(2), 91-99.

Ashkanasy, N., Wilderom, C. P. M., \& Peterson, M. F. (2000). The handbook of organizational culture and climate. Thousand Oaks: Sage Publications.

Ayers, S., \& Kaplan, S. E. (2005). Wrongdoing by consultants: An examination of employees' reporting intentions. Journal of Business Ethics, 57, 121-137. https://doi.org/10.1007/s1055 1-004-4600-0.

Baker, T. L., Hunt, T. G., \& Andrews, M. C. (2006). Promoting ethical behavior and organizational citizenship behaviors: The influence of corporate ethical values. Journal of Business Research, 59(7), 849-857. https://doi.org/10.1016/j.jbusres.2006.02.004.

Bandura, A. (1977). Social learning theory. Englewood Cliffs: Prentice-Hall.

Barley, S. (1986). Technology as an occasion for structuring: Evidence from observations of CT scanners and the social order of radiology departments. Administrative Science Quarterly, 31(1), 78-108.

Bedi, A., Alpaslan, C. M., \& Green, S. (2016). A meta-analytic review of ethical leadership outcomes and moderators. Journal of Business Ethics, 139(3), 517-536.

Bell, E. (1990). The bicultural life experience of career-oriented black women. Journal of Organizational Behavior, 11(6), 459-477.

Bliese, P. D. (1998). Group size and measures of group-level properties: An examination of eta-squared and ICC values. Journal of Management, 24, 157-172.

Bliese, P. D. (2000). Within-group agreement, non-independence, and reliability: Implications for data aggregation and analysis. In Multilevel theory, research, and methods in organizations. San Francisco: Jossey-Bass.

Brunsson, N., \& Sahlin-Andersson, K. (2000). Constructing organizations: The example of public sector reform. Organization Studies, 21(4), 721-746.

Burnaz, S., Atakan, M. G. S., Topcu, Y. I., \& Singhapakdi, A. (2009). An exploratory cross-cultural analysis of marketing ethics: The case of Turkish, Thai, and American businesspeople. Journal of Business Ethics, 90(3), 371-382. https://doi.org/10.1007/s1055 1-010-0422-4

Caldwell, D. F., \& Moberg, D. (2007). An exploratory investigation of the effect of ethical culture in activating moral imagination. Journal of Business Ethics, 73, 193-204.

Chao, G. T. (2000). Multilevel issues and culture: An integrative view. In K. J. Klein \& S. W. J. Kozlowsk (Eds.), Multilevel theory, research, and methods in organizations: Foundations, extensions, and new directions (pp. 308-346). San Francisco: Jossey-Bass.

De Vries, R. E., \& van Gelder, J. (2015). Explaining workplace delinquency: The role of honesty-humility, ethical culture, and employee surveillance. Personality and Individual Differences, 86, 112-116. https://doi.org/10.1016/j.paid.2015.06.008.

DeBode, J. D., Armenakis, A. A., Feild, H. S., \& Walker, A. G. (2013). Assessing ethical organizational culture: Refinement of a scale. Journal of Applied Behavioral Science, 49(4), 460-484. https:// doi.org/10.1177/0021886313500987.
Denison, D. R. (1996). What is the difference between organizational culture and organizational climate ? A native's point of view on a decade of paradigm wars. The Academy of Management Review, 21(3), 619-654.

Desplaces, D. E., Melchar, D. E., Beauvais, L. L., \& Bosco, S. M. (2007). The impact of business education on moral judgment competence: An empirical study. Journal of Business Ethics Journal of Business Ethics, 74(1), 73-87. https://doi.org/10.1007/s1055 1-006-9221-3.

Douglas, P. C., Davidson, R. A., \& Schwartz, B. N. (2001). The effect culture orientation of organizational and ethical on accountants' ethical judgments. Journal of Business Ethics, 34(2), 101-121. https://doi.org/10.1023/A:1012261900281.

Earley, C., \& Mosakowski, E. (2000). Creating hybrid team cultures: An empirical test of transnational team functioning. Academy of Management, 43(1), 26-49.

George, J. M. (1990). Personality, affect, and behavior in groups. Journal of Applied Psychology, 75, 107-116.

Gino, F., Ayal, S., \& Ariely, D. (2009). Contagion and differentiation in unethical behavior: The effect of one bad apple on the barrel. Psychological Science, 20(3), 393-398.

Glick, W. H. (1985). Conceptualizing and measuring organizational and psychological climate: Pitfalls in multilevel research. Academy of Management Review, 10(3), 601-616. https://doi. org/10.5465/amr.1985.4279045.

Glisson, C., \& James, L. (2002). The cross-level effects of culture and climate in human service teams. Journal of Organizational Behavior, 23(23), 767-794. https://doi.org/10.1002/job.162.

Hofstede, G. (1998a). Identifying organizational subcultures: An empirical approach. Journal of Management Studies, 35(1), 1-12. https://doi.org/10.1111/1467-6486.00081.

Hofstede, G. (1998b). Think locally, act globally: Cultural constraints in personnel management. In W. Weber \& M. Festing (Eds.), Management and international review. Wiesbaden: Gabler Verlag.

Huang, L., \& Paterson, T. A. (2017). Group ethical voice: Influence of ethical leadership and impact on ethical performance. Journal of Management, 43(4), 1157-1184. https://doi.org/10.1007/s1055 1-004-4600-0.

Huhtala, M., Feldt, T., Hyvönen, K., \& Mauno, S. (2013). Ethical organisational culture as a context for managers' personal work goals. Journal of Business Ethics, 114(2), 265-282. https://doi. org/10.1007/s10551-012-1346-y.

Huhtala, M., Feldt, T., Lämsä, A. M., Mauno, S., \& Kinnunen, U. (2011). Does the ethical culture of organisations promote managers' occupational well-being? Investigating indirect links via ethical strain. Journal of Business Ethics, 101(2), 231-247. https://doi.org/10.1007/s10551-010-0719-3.

Huhtala, M., Kangas, M., Kaptein, M., \& Feldt, T. (2018). The shortened corporate ethical virtues scale: Measurement invariance and mean differences across two occupational groups. Business Ethics: A European Review, 27, 238-247. https://doi. org/10.1111/beer.12184.

Huhtala, M., Kaptein, M., \& Feldt, T. (2016). How perceived changes in the ethical culture of organizations influence the well-being of managers: A two-year longitudinal study. European Journal of Work and Organizational Psychology, 25(3), 335-352. https ://doi.org/10.1080/1359432X.2015.1068761.

Huhtala, M., Tolvanen, A., Mauno, S., \& Feldt, T. (2015). The associations between ethical organizational culture, burnout, and engagement: A multilevel study. Journal of Business and Psychology, 30(2), 399-414. https://doi.org/10.1007/s1086 9-014-9369-2.

Hunt, S. D., Wood, V. R., \& Chonko, L. B. (1989). Corporate ethical values and organizational commitment in marketing. Journal of Marketing, 53(3), 79-90. https://doi.org/10.2307/1251344. 
James, L., Demaree, R., \& Wolf, G. (1993). Rwg: An assessment of within-group interrater agreement. Journal of Applied Psychology, 75, 306-329.

Jung, J., Nam, C., Lee, E., \& Kim, S. (2015). Subculture by autonomy and group cohesion and its effect on job satisfaction of R\&D professionals in an R\&D organization. Journal of Management \& Organization, 22, 154-172.

Kangas, M., Kaptein, M., Huhtala, M., Lämsä, A. M., Pihlajasaari, P., \& Feldt, T. (2016). Why do managers leave their organization? Investigating the role of ethical organizational culture in managerial turnover. Journal of Business Ethics, 153(3), 1-17. https://doi. org/10.1007/s10551-016-3363-8.

Kangas, M., Muotka, J., Huhtala, M., Mäkikangas, A., \& Feldt, T. (2017). Is the ethical culture of the organization associated with sickness absence? A multilevel analysis in a public sector organization. Journal of Business Ethics, 140(1), 131-145. https://doi. org/10.1007/s10551-015-2644-y.

Kaptein, M. (2008). Developing and testing a measure for the ethical culture of organizations: The corporate ethical virtues model. Journal of Organizational Behavior, 29(7), 923-947. https://doi. org/10.1002/job.520.

Kaptein, M. (2009). Ethics programs and ethical culture: A next step in unraveling their multi-faceted relationship. Journal of Business Ethics, 89(2), 261-281. https://doi.org/10.1007/s1055 1-008-9998-3.

Kaptein, M. (2010). The ethics of organizations: A longitudinal study of the US working population. Journal of Business Ethics, 92(4), 601-618. https://doi.org/10.1007/s10551-009-0175-0.

Kaptein, M. (2011a). Understanding unethical behavior by unraveling ethical culture. Human Relations, 64(6), 843-869. https://doi. org/10.1177/0018726710390536.

Kaptein, M. (2011b). From inaction to external whistleblowing: The influence of the ethical culture of organizations on employee responses to observed wrongdoing. Journal of Business Ethics, 98(3), 513-530. https://doi.org/10.1007/s10551-010-0591-1.

Kaptein, M. (2015). The effectiveness of ethics programs: The role of scope, composition, and sequence. Journal of Business Ethics, 132(2), 415-431. https://doi.org/10.1007/s10551-014-2296-3.

Kaptein, M., \& van Dalen, J. (2000). The empirical assessment of corporate ethics: A case study. Journal of Business Ethics, 24(2), 95-114. https://doi.org/10.1023/A:1006360210646.

Keith, N., Pettijohn, C. E., \& Burnett, M. S. (2003). An empirical evaluation of the effect of peer and managerial ethical behaviors and the ethical predispositions of prospective advertising employees. Journal of Business Ethics, 48, 251-265.

Koh, H. C., \& Boo, E. H. Y. (2004). Organisational ethics and employee satisfaction and commitment. Management Decision, 42(5), 677-693. https://doi.org/10.1108/00251740410538514.

Kok, A. M., de Bakker, F. G. A., \& Groenewegen, P. (2017). Sustainability struggles: Conflicting cultures and incompatible logics. Business \& Society. https://doi.org/10.1177/0007650317703644.

Latan, H., Ringle, C. M., \& Jabbour, C. J. C. (2018). Whistleblowing intentions among public accountants in Indonesia: Testing for the moderation effects. Journal of Business Ethics, 152(2), 573-588. https://doi.org/10.1007/s10551-016-3318-0.

LeBreton, J., \& Senter, J. (2008). Answers to 20 questions about interrater reliability and interrater agreement. Organizational Research Methods, 11(4), 815-852.

Liden, R. C., Wayne, S. J., Liao, C., \& Meuser, J. D. (2014). Servant leadership and serving culture: Influence on individual and unit performance. Academy of Management Journal, 57(5), 14341452. https://doi.org/10.5465/amj.2013.0034.

Liu, G., Amini, M. M., Babakus, E., \& Stafford, M. B. R. (2011). Handling observations with low interrater agreement values. Journal of Analytical Sciences, Methods and Instrumentation, 1(2), 9-18. https://doi.org/10.4236/jasmi.2011.12002.
MacLean, T., Litzky, B. E., \& Holderness, D. K. (2015). When organizations don't walk their talk: A cross-level examination of how decoupling formal ethics programs affects organizational members. Journal of Business Ethics, 128(2), 351-368. https://doi. org/10.1007/s10551-014-2103-1.

Maloney, M., Johnson, S., \& Zellmer-Bruhn, M. (2010). Assessing group-level constructs under missing data conditions: A Monte Carlo simulation. Small Group Research, 41(3), 281-307.

Martin, J. (2002). Organisational culture: Mapping the terrain. Thousand Oaks, CA: Sage Publications.

Mayer, D. M. (2014). A review of the literature on ethical climate and culture. In B. Schneider \& K. Barbera (Eds.), The Oxford handbook of organizational climate and culture (pp. 415-442). New York, NY: Oxford University Press.

Nunnally, J. C. (1978). Psychometric theory. New York: McGraw-Hill.

Park, H., \& Blenkinsopp, J. (2013). The impact of ethics programmes and ethical culture on misconduct in public service organizations. International Journal of Public Sector Management, 26(7), 520533. https://doi.org/10.1108/IJPSM-01-2012-0004.

Pierce, B., \& Sweeney, B. (2010). The Relationship between demographic variables and ethical decision making of trainee accountants. International Journal of Auditing, 14, 79-99. https://doi.org /10.1111/j.1099-1123.2009.00404.x.

Podsakoff, P., MacKenzie, S., Lee, J., \& Podsakoff, N. (2003). Common method biases in behavioral research: A critical review of the literature and recommended remedies. Journal of Applied Psychology, 88(5), 879-903.

Pučètaitè, R., Novelskaitè, A., Lämsä, A. M., \& Riivari, E. (2016). The relationship between ethical organisational culture and organisational innovativeness: Comparison of findings from Finland and Lithuania. Journal of Business Ethics, 139(4), 685-700. https://doi.org/10.1007/s10551-016-3051-8.

Riivari, E., \& Lämsä, A. M. (2014). Does it pay to be ethical? Examining the relationship between organisations' ethical culture and innovativeness. Journal of Business Ethics, 124(1), 1-17. https ://doi.org/10.1007/s10551-013-1859-z.

Riivari, E., Lämsä, A. M., Kujala, J., \& Heiskanen, E. (2012). The ethical culture of organisations and organisational innovativeness. European Journal of Innovation Management, 15(3), 310-331. https://doi.org/10.1108/14601061211243657.

Ruiz-Palomino, P., \& Martínez-Cañas, R. (2014). Ethical culture, ethical intent, and organizational citizenship behavior: The moderating and mediating role of person-organization Fit. Journal of Business Ethics, 120(1), 95-108. https://doi.org/10.1007/ s10551-013-1650-1.

Ryan, T. P. (1997). Modern regression method. New York: Wiley.

Sackmann, S. A. (1997). Cultural complexity in organizations: Inherent contrasts and contradictions. Thousand Oaks: SAGE Publications Inc.

Sackmann, S. A. (2011). Culture and performance. In N. M. Ashkanasy, C. P. Wilderom, \& M. F. Peterson (Eds.), The handbook of organizational culture and climate (pp. 188-224). Thousand Oaks, CA: SAGE Publications Inc. https://doi. org/10.4135/9781483307961.n12.

Schaubroeck, J., Hannah, S., Avolio, B., Kozlowski, S., Lord, R., Treviño, L. K., et al. (2012). Embedding ethical leadership within and across organizational levels. Academy of Management Journal, 55(5), 1053-1078. https://doi.org/10.5465/ ainj.2011.0064.

Schein, E. (2007). Organizational culture and leadership (3rd ed.). San Francisco: Jossey-Bass.

Schneider, B., Ehrhart, M. G., \& Macey, W. (2013). Organizational climate and culture. Annual Review of Psychology, 64, 361-388. https://doi.org/10.1146/annurev-psych-113011-143809.

Schneider, B., González-Romá, V., Ostroff, C., \& West, M. A. (2017). Organizational climate and culture: Reflections on the history of 
the constructs in the journal of applied psychology. Journal of Applied Psychology, 102(3), 468-482. https://doi.org/10.1037/ ap10000090.

Scholten, W., \& Ellemers, N. (2016). Bad apples or corrupting barrels? Preventing traders' misconduct. Journal of Financial Regulation and Compliance, 24(4), 366-382. https://doi.org/10.1108/ MRR-09-2015-0216.

Sharma, D., Borna, S., \& Stearns, J. J. M. (2009). An investigation of the effects of corporate ethical values on employee commitment and performance: Examining the moderating role of perceived fairness. Journal of Business Ethics, 89(2), 251-260. https://doi. org/10.1007/s10551-008-9997-4.

Shin, Y., Choi, J. N., \& Lee, S. (2015). Do team culture matter? Roles of team culture and collective regulatory focus in team task and creative performance. Group \& Organization Management, 41(2), 232-265. https://doi.org/10.1177/1059601115584998.

Shin, S. J., Kim, T. Y., Lee, J. Y., \& Bian, L. (2012). Cognitive team diversity and individual team member creativity: A cross-level interaction. Academy of Management Journal, 55(1), 197-212. https://doi.org/10.5465/amj.2010.0270.

Smith-Crowe, K., Tenbrunsel, A. E., Chan-Serafin, S., Brief, A. P., Umphress, E. E., \& Joseph, J. (2015). The ethics "fix": When formal systems make a difference. Journal of Business Ethics, 131(4), 791-801. https://doi.org/10.1007/s10551-013-2022-6.

Soeters, J. (2018). Organizational cultures in the military. In G. Caforio \& M. Nuciari (Eds.), The handbook of the sociology of the military. Cham, Switzerland: Springer.

Sweeney, B., Arnold, D., \& Pierce, B. (2010). The impact of perceived ethical culture of the firm and demographic variables on auditors' ethical evaluation and intention to act decisions. Journal of Business Ethics, 93(4), 531-551. https://doi.org/10.1007/s1055 1-009-0237-3.

Treviño, L., Butterfield, K., \& McCabe, D. (1998). The ethical context in organizations: Influences on employee attitudes and behaviors. Business Ethics Quarterly, 8(3), 447-476.

Treviño, L. K., Den Nieuwenboer, N., \& Kish-Gephart, J. J. (2014). (Un)Ethical behavior in organizations. Annual Review of Psychology, 65, 635-660. https://doi.org/10.1146/annurev-psych-11301 $1-143745$.

Treviño, L. K., Weaver, G., Gibson, D., \& Toffler, B. (1999). Managing ethics and legal compliance: What works and what hurts. California Management Review, 41(2), 131-151.

Treviño, L. K., Weaver, G. R., \& Reynolds, S. J. (2006). Behavioral ethics in organizations: A review. Journal of Management, 32(6), 951-990.

Trice, H., \& Beyer, J. (1993). The cultures of work organizations. Englewood Cliffs: Prentice-Hall Inc.

Tsai, M.-T., \& Shih, C.-M. (2005). The influences of organizational and personal ethics on role conflict among marketing managers: An empirical investigation. International Journal of Management, 22(1), 54-61.

Valentine, S. (2009). Ethics training, ethical context, and sales and marketing professionals' satisfaction with supervisors and coworkers. Journal of Personal Selling \& Sales Management, 29(3), 227-242. https://doi.org/10.2753/PSS0885-3134290302.

Valentine, S., \& Barnett, T. (2007). Perceived organizational ethics and the ethical decisions of sales and marketing personnel. Journal of
Personal Selling \& Sales Management, 27(4), 373-388. https:// doi.org/10.2753/PSS0885-3134270407.

Valentine, S., Godkin, L., Fleischman, G. M., Kidwell, R., Journal, S., February, N., et al. (2011). Corporate ethical values, group creativity, job satisfaction and turnover intention: The impact of work context on work response. Journal of Business Ethics, 98(3), 353-372. https://doi.org/10.1007/s10551-010-0554-6.

Valentine, S., Godkin, L., \& Lucero, M. (2002). Ethical context, organizational commitment, and person- organization fit. Journal of Business Ethics, 41(4), 349-360. https://doi.org/10.1023/A:10212 03017316.

Van Maanen, J., \& Barley, S. (1984). Occupational communities: Culture and control in organizations. Research in Organizational Behavior, 6, 287-365.

van Marrewijk, A. (2016). Conflicting subcultures in mergers and acquisitions: A longitudinal study of integrating a radical internet firm into a bureaucratic telecoms firm. British Journal of Management, 27(2), 1-17. https://doi.org/10.1111/1467-8551.12135.

Vitell, S. J., \& Hidalgo, E. R. (2006). The impact of corporate ethical values and enforcement of ethical codes on the perceived importance of ethics in business: A comparison of U.S. and Spanish managers. Journal of Business Ethics, 64(1), 31-43. https://doi. org/10.1007/s10551-005-4664-5.

Warren, D. E., Gaspar, J. P., \& Laufer, W. S. (2014). Is formal ethics training merely cosmetic? A study of ethics training and ethical organizational culture. Business Ethics Quarterly, 24(01), 85-117. https://doi.org/10.5840/beq2014233.

Webb, W. N. (2012). Ethical culture and the value-based approach to integrity management: A case study of the department of correctional services. Public Administration and Development, 13(2), 96-108. https://doi.org/10.1002/pad.

Zaal, R. O. S., Jeurissen, R. J. M., \& Groenland, E. A. G. (2017). Organizational architecture, ethical culture, and perceived unethical behavior towards customers: Evidence from wholesale banking. Journal of Business Ethics. https://doi.org/10.1007/s1055 1-017-3752-7.

Zellmer-Bruhn, M., \& Gibson, C. (2006). Multinational organization context: Implications for team learning and performance. Academy of Management Journal, 49(3), 501-518. https://doi. org/10.5465/amj.2006.21794668.

Zhang, J., Chiu, R., \& Wei, L. (2009a). Decision-making process of internal whistleblowing behavior in China: Empirical evidence and implications. Journal of Business Ethics, 88(1), 25-41. https ://doi.org/10.1007/s10551-008-9831-z.

Zhang, J., Chiu, R., \& Wei, L. Q. (2009b). On whistleblowing judgment and intention: The roles of positive mood and organizational ethical culture. Journal of Managerial Psychology, 24(7), 627-649. https://doi.org/10.1108/02683940910989020.

Zuber, F. (2015). Spread of unethical behavior in organizations: A dynamic social network perspective. Journal of Business Ethics, 131(1), 151-172.

Publisher's Note Springer Nature remains neutral with regard to jurisdictional claims in published maps and institutional affiliations. 